\title{
Fatal Outcome after Delayed Pipeline Embolization Device Migration for the Treatment of a Giant Superior Cerebellar Artery Aneurysm: Technical Note for Complication Avoidance
}

\author{
Ramón Navarro', Edison J. Cano ${ }^{1}$, Leonardo B. C. Brasiliense'1, Guilherme Dabus², \\ Ricardo A. Hanel ${ }^{1}$ \\ ${ }^{1}$ Department of Neurosurgery, Mayo Clinic, Jacksonville, FL, USA \\ ${ }^{2}$ Interventional Neuroradiology, Baptist Cardiac and Vascular Institute, Miami, USA \\ Email: Navarro.balbuena@gmail.com
}

Received 26 June 2014; revised 26 July 2014; accepted 26 August 2014

Copyright (C) 2014 by authors and Scientific Research Publishing Inc.

This work is licensed under the Creative Commons Attribution International License (CC BY). http://creativecommons.org/licenses/by/4.0/

(c) (i) Open Access

\begin{abstract}
Purpose: Flow diversion is a relatively novel technique to treat some intracranial aneurysms. With new techniques, unusual complications can occur. We described a case of Pipeline Embolization Device (PED) migration, strategy for its recognition, and a technical point to prevent its occurrence. Publication of these rare events is important to make physicians aware of potential complications. Methods: A patient with a previously coiled giant superior cerebellar aneurysm presented with brainstem compression symptoms. Imaging verified progressive aneurysm growth. A decision was made to treat the aneurysm with PED. Results: Development of new neurologic symptoms prompted a computed tomography that showed hydrocephalus. An angiogram also showed recanalization of the aneurysm secondary to upward migration/retraction of the flow diverter. A ventriculo-peritoneal shunt was implemented and planning for placement of a second flow diverter was made. Unfortunately, the patient expired while waiting for the endovacular intervention. Conclusions: PED migration may occur even after correct placement of the device. Early recognition of this complication is essential. When clinical changes occur, it is paramount that this uncommon, but potentially deadly, complication is suspected. Appropriate sizing and deployment technique are important for the long-term stability of the device.
\end{abstract}

\section{Keywords}

Giant Intracranial Aneurysm, Endovascular Treatment, Flow Diverter, Complication, Migration 


\section{Introduction}

The use of flow diverters for the treatment of brain aneurysm represents an important milestone for the field [1]. The Pipeline Embolization Device (PED; ev3, Irvine, California, USA) is a relatively new device for the endovascular treatment of intracranial aneurysms, with increased utilization globally because of its positive results [2]. PED has been mainly used for the treatment of anterior circulation, large/giant, wide-necked, blister-like, and dissecting aneurysms [3]-[5]. It can also be a rescue therapy for unsuccessfully treated lesions after coiling [6].

As flow diversion use increases, new complications are becoming apparent [7]-[10]. PED migration has been described on imaging findings during follow-up in only six published cases [7] [9]. We present a case of posterior circulation PED foreshortening and migration leading to aneurysm changes and a fatal subarachnoid hemorrhage. Possible causes for migration and strategies to avoid, detect, and manage migration are discussed. Also, we perform a brief review of the literature where early angiographic images have been suggested to evaluate patients for device migration [7].

\section{Case Report}

An elderly patient with a history of a right giant superior cerebellar artery (SCA) aneurysm presented with worsening left-sided hemiparesis and gait impairment. The patient had a previous history of a subarachnoid hemorrhage that was initially treated by coiling about a year and a half before and was treated again with coiling for recurrence six months prior to presentation. During physical exam, the patient was awake, alert, and oriented with intact cranial nerve examination; marked left-sided weakness was noted. Cerebral angiogram demonstrated the presence of coil mass at the position of the right SCA aneurysm with residual aneurysm filling (Figure 1(A)). Magnetic resonance imaging (MRI) showed a partially coiled aneurysm with a large thrombosed portion beyond the coil mass and significant brainstem compression with T2 abnormalities suggestive of perilesional inflammation. Therapeutic options of primary clipping basilar artery sacrifice or endovascular treatment were addressed. A decision was made for off-label use of the PED. The patient received a dual anti-platelet regimen with the therapeutic function of both aspirin and clopidogrel, obtained prior to treatment. The flow diverter was deployed using a 6Fr Neuron 070 guiding catheter (Penumbra, Alameda, CA) and a Marksman microcatheter (ev3 Endovascular, Plymouth, MN). A single PED measuring $4 \mathrm{~mm} \times 14 \mathrm{~mm}$ was placed from the right P1 segment of the posterior cerebral artery into the upper third of the basilar trunk with good neck coverage and vessel apposition (Figure 1(B)). The procedure was uneventful, and the patient was dismissed with no new neurological deficits.
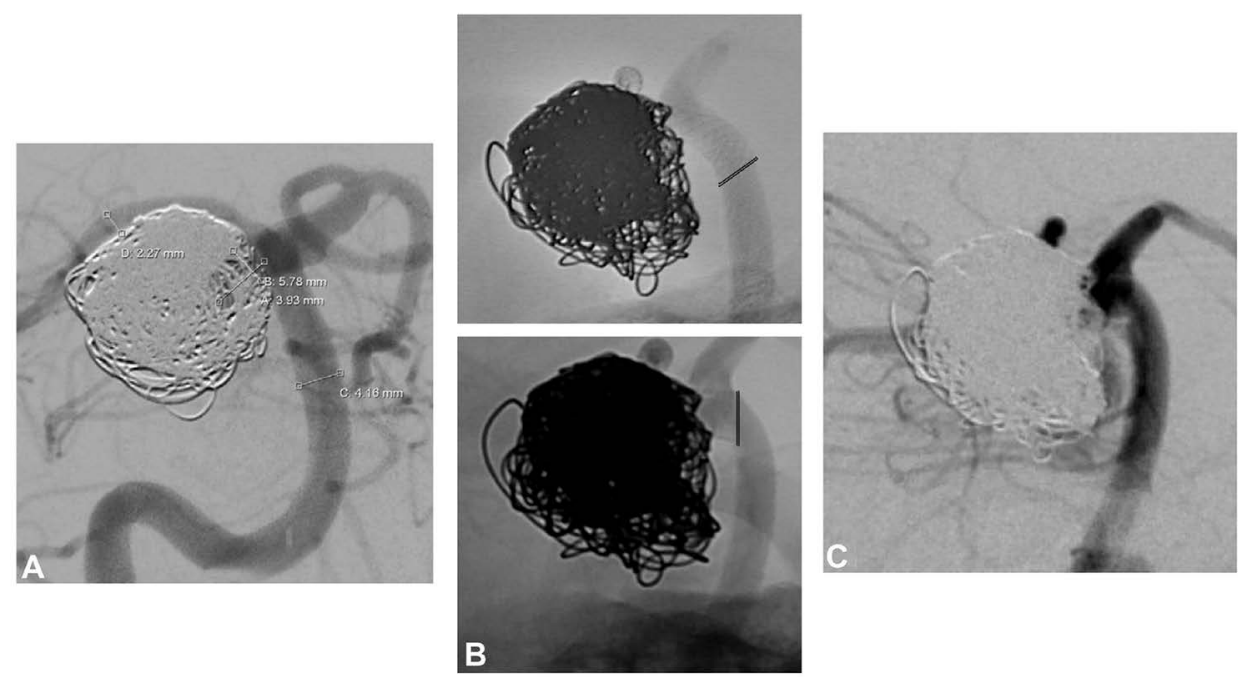

Figure 1. (A) Residual right superior cerebellar artery aneurysm after two previous coiling attempts. ((B), upper) Angiogram after initial placement of the Pipeline Embolization Device (PED) across the neck of the aneurysm. ((B), lower) Follow-up angiogram that, allowing for some angulation difference, shows upward migration of the PED (C) with recurrent filling of the aneurysm; (B) Double black lines indicate the proximal end of the PED. 


\section{Complication}

Approximately a week after the procedure, the patient presented with diplopia, which was worse at right lateral gaze. Head computed tomography (CT) demonstrated no new hemorrhage, and the patient was started on $4 \mathrm{mg}$ of dexamethasone treatment every six hours for one week, which improved symptoms. Nine weeks after the flow diverter placement, the patient presented with confusion and gait instability. Head CT showed incipient hydrocephalus and a possible worsening mass effect in the brainstem. Lumbar puncture revealed opening pressure of $9.5 \mathrm{~cm} \mathrm{H2O}$. MRI of the brain demonstrated an increase in ventricular size. A metabolic or infectious etiology for the patient's change in neurologic status was also sought. The patient's white blood cell count was of 21,800 per mL, and a chest x-ray revealed opacity in the left lung base, which was suspicious for pneumonia. Antibiotic therapy with piperacillin and tazobactam was started, and by the following morning the patient's mental status improved drastically. CT angiogram of the chest was negative for pulmonary embolus, but it did confirm the patient's aspiration/community-acquired pneumonia. The patient was discharged once his condition improved. Decision was made to temporarily discontinue clopidogrel in the face of potential shunting. A follow-up visit two weeks later revealed further neurological deterioration, and a neurological exam revealed right VI nerve palsy.

Head CT showed worsening hydrocephalus (Figure 2), and an emergent ventricular-peritoneal shunt (VPS) was placed. After shunting, the patient's overall alertness and gait improved. At the same admission, a cerebral angiogram was performed to assess the obliteration of the aneurysm, which revealed anterograde PED migration/foreshortening; the proximal aspect of the PED migrated upwards and the aneurysm neck was only partially covered. In addition, a change in the pattern of residual aneurysm filling with a growth of the remnant was noted (Figure 1(C)). Options of basilar sacrifice vs treatment with a second flow diverter were discussed with the patient and family. A decision was made for treatment with an additional PED that would partially overlap with the previously placed flow diverter and would extend inferiorly to the mid-basilar trunk. Since the patient had undergone a VPS placement within 24 hours, treatment was scheduled for two weeks after VPS insertion in order to be able to reinstitute the dual anti-platelet regimen.

Less than two weeks after VPS, the patient developed a headache and became comatose. The patient was admitted to an outside Emergency Department and was found to be unresponsive to deep noxious stimulus, with minimal pupillary reflexes, and no corneal or oculocephalic reflexes. A head CT revealed a massive subarachnoid hemorrhage with a thalamic hematoma with an $8 \mathrm{~mm}$ right to left midline shift plus an intraventricular hemorrhage (Figure 3). Given the clinical conditions, a decision was made to not intervene, and the patient expired.
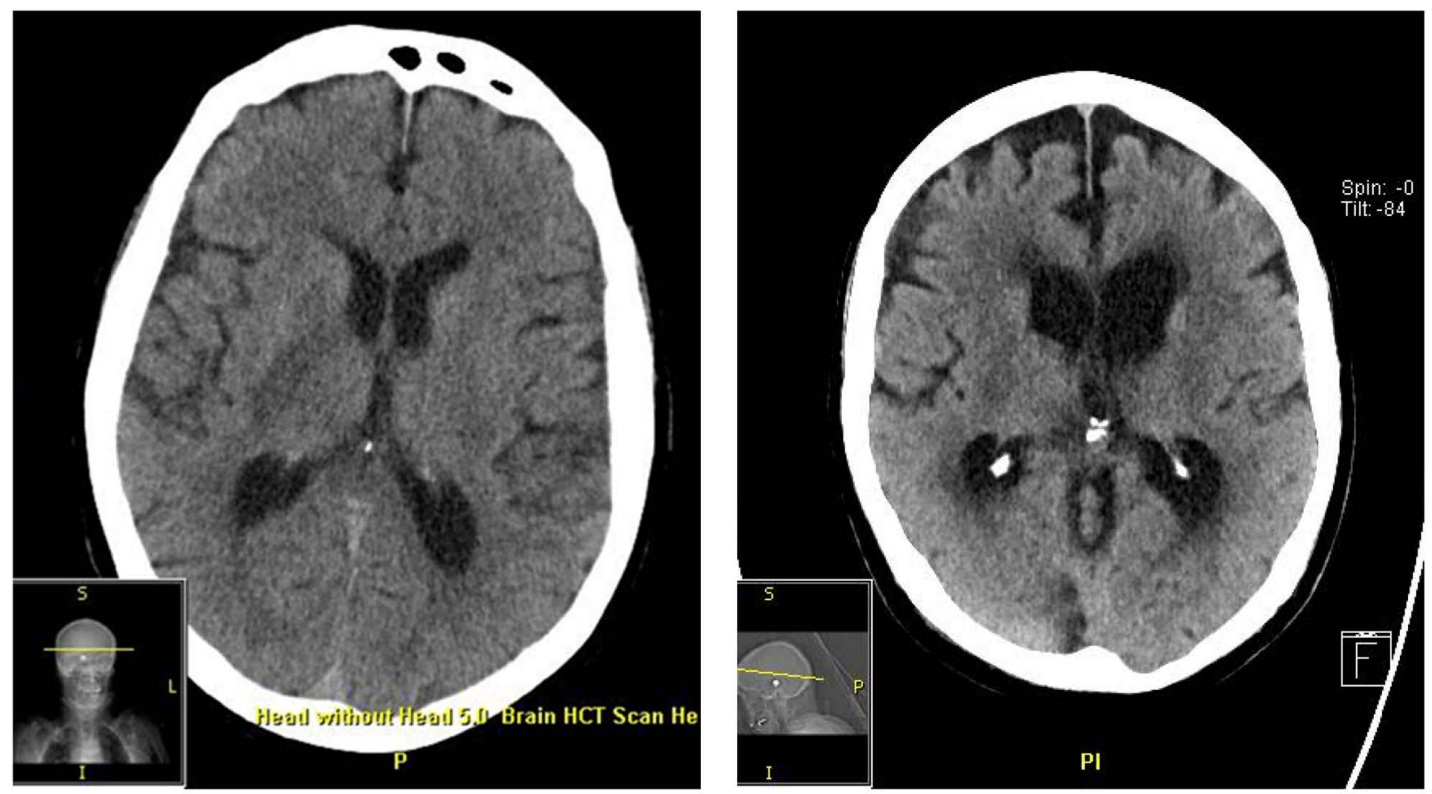

Figure 2. Interval development of hydrocephalus alters treatment with PED. 


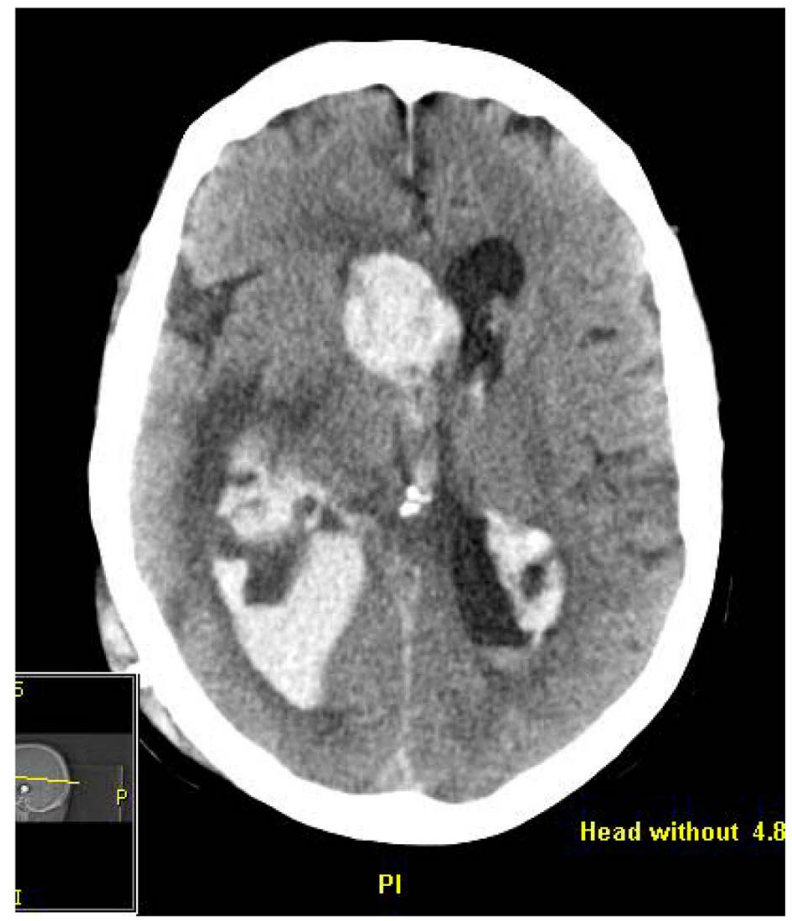

Figure 3. Massive intraventricular hemorrhage less than two weeks after ventricular-peritoneal shunt placement.

\section{Discussion}

Endoluminal reconstruction of an intracranial aneurysm using flow diversion is gaining popularity as a reliable treatment for large and giant intracranial aneurysms. The PED is a flexible self-expanding, micro-catheter delivered, high metal surface area coverage, stent-like device that is currently used for flow diversion. This device is available in 2.5 - $5.00 \mathrm{~mm}$ diameters and is 10 - $35 \mathrm{~mm}$ in length. Compared to other intracranial self-expanding stents, proper PED placement is more demanding, and the behavior of the device during deployment can be somewhat unpredictable. For example, due to its flexibility, the device can foreshorten up to 50\%. Moreover, the operator must have in mind that until scarring and endothelization of the device occurs, the accordion-like behavior of the device and its elasticity raises the risk for movement of the PED inside the vessel, either by migration or by retraction.

Two previous reports of PED migration have been identified in the literature with a total of six cases reported [7] [9]. Chalouhi et al. [7] have reported the largest series with a total of five patients. In two of them, the outcome after device migration had catastrophic consequences. Following their review, they made several procedural recommendations. First, they suggest using longer flow-diverters when there is a significant mismatch in luminal diameter between the inflow vessel and the outflow vessel. Second, they recommend avoiding excessive dragging of the device and avoid stretching of the PED to prevent delayed "accordion effect". We agree with Chalouhi et al. in that several important technical points have to be considered when deploying a PED; advancing the PED, rather than unsheathing it and intermittently applying forward force on the construct by pushing both the wire and the microcatheter together. This maneuver helps lock the device in place making the final placement more stable. Finally, they suggest confirming good PED-vessel wall apposition at the end of the procedure using cone beam three-dimensional CT reconstructions. In addition, McTaggart et al. [9] described an "early" retraction of a PED in a patient that was being treated for a fusiform vertebral artery aneurysm in the setting of an acute subarachnoid hemorrhage. On a control angiogram, to evaluate for the presence of vasospasm about a week after the initial procedure, they found that the PED had retracted distally, leaving part of the aneurysm unprotected. To manage this situation, they telescoped another PED inside the one that was previously placed. An important point they made is that during the vasospasm period, it is even more difficult to get reliable measurements of the vessel diameter, and the chances of incorrect flow-diverter size selection increases. There 
have also been two previous cases of SILK flow diverter (Balt Extrusion, Montmorency, France) migration, one of which led to a fatal re-bleeding, similar to our case [8] [10]. Authors with published experience with flow diverters agree that careful size and length selection is critical to avoid unwanted migration of the device. Lubicz et al. suggest choosing a longer length to ensure good stability and a stent diameter $0.25-0.50 \mathrm{~mm}$ larger than the distal parent artery diameter, as in our case [11]. In retrospect, the PED in our case might have been too short. Telescoping of another PED might have been helpful to avoid this complication. There have been other reports regarding intracranial stent migration while using Enterprise stents (Cordis, Miami Lakes, Florida), and most of these reports were located in constructs similar to ours in the posterior circulation (basilar trunk-posterior cerebral artery). These migrations were mostly retrograde from the posterior cerebral artery into the basilar artery or the basilar tip aneurysm [12] [13]. However, due to the mechanical properties of the Enterprise stents, comparisons between these stents might not be adequate.

Delayed PED migration is likely silent in most cases. When clinical changes occur, it is paramount that this uncommon, but potentially deadly, complication is suspected during differential diagnosis. In the present case, the exact time of the migration or retraction of the PED is impossible to determine. Animal studies demonstrated stent endothelization around four weeks, after which stent migration was less likely [14]. Unless migration occurs at the time of implant, dislodgment will not be noticed until further imaging with catheter-based cerebral angiography. Immediate mass effect after flow diversion for giant aneurysms is not rare and is generally managed with a course of steroids, as in our case. However, the patient had a clear and delayed neurological deterioration more than two months after the PED implant date, leading us to think that migration occurred at that point. At that time, we also entertained the possibility that our patient's symptoms were related to progressive thrombosis of the aneurysm with mass effect to the aqueduct and secondary hydrocephalus. Hydrocephalus has been occasionally described after coiling, even without mass effect to the cerebrospinal fluid pathways [15]. In retrospect, an earlier than planned catheter-based angiography or intravenous cone beam three-dimensional CT reconstructions would have revealed the device migration. Although a CT angiogram can demonstrate the position of the flow diverter, the presence of a large coil mass precluded conventional CT-based imaging utilization in the present case.

\section{Conclusion}

PED migration may occur even after correct placement of the device. Recurring and worsening symptoms should prompt urgent imaging with CT-based or catheter-based angiography to ensure the correct positioning of the device. When clinical changes occur, it is paramount that this uncommon, but potentially deadly, complication is suspected. Appropriate sizing and deployment technique are important for long term stability of the PED.

\section{Acknowledgements}

None.

\section{References}

[1] Lylyk, P., Miranda, C., Ceratto, R., Ferrario, A., Scrivano, E., Luna, H.R., Berez, A.L., Tran, Q., Nelson, P.K. and Fiorella, D. (2009) Curative Endovascular Reconstruction of Cerebral Aneurysms with the pipeline Embolization Device: the Buenos Aires Experience. Neurosurgery, 64, 632-642; Discussion, 642-633; Quiz, N636.

[2] Tse, M.M., Yan, B., Dowling, R.J. and Mitchell, P.J. (2013) Current Status of Pipeline Embolization Device in the Treatment of Intracranial Aneurysms: A Review. World Neurosurgery, 80, 829-835.

[3] Chitale, R., Gonzalez, L.F., Randazzo, C., Dumont, A.S., Tjoumakaris, S., Rosenwasser, R., Chalouhi, N., Gordon, D. and Jabbour, P. (2012) Single Center Experience with Pipeline Stent: Feasibility, Technique, and Complications. Neurosurgery, 71, 679-691; Discussion, 691. http://dx.doi.org/10.1227/NEU.0b013e318260fe86

[4] Kan, P., Siddiqui, A.H., Veznedaroglu, E., Liebman, K.M., Binning, M.J., Dumont, T.M., Ogilvy, C.S., Gaughen Jr., J.R., Mocco, J., Velat, G.J., Ringer, A.J., Welch, B.G., Horowitz, M.B., Snyder, K.V., Hopkins, L.N. and Levy, E.I. (2012) Earlypostmarket Results after Treatment of Intracranial Aneurysms with the Pipeline Embolization Device: A U.S. Multicenter Experience. Neurosurgery, 71, 1080-1087; Discussion, 1087-1088. http://dx.doi.org/10.1227/NEU.0b013e31827060d9

[5] Saatci, I., Yavuz, K., Ozer, C., Geyik, S. and Cekirge, H.S. (2012) Treatment of Intracranial Aneurysms Using the Pipeline Flow-Diverter Embolization Device: A Single-Center Experience with Long-Term Follow-Up Results. Amer- 
ican Journal of Neuroradiology, 33, 1436-1446. http://dx.doi.org/10.3174/ajnr.A3246

[6] Fischer, S., Vajda, Z., Aguilar Perez, M., Schmid, E., Hopf, N., Bazner, H. and Henkes, H. (2012) Pipeline Embolization Device (PED) for Neurovascular Reconstruction: Initial Experience in the Treatment of 101 Intracranial Aneurysms and Dissections. Neuroradiology, 54, 369-382. http://dx.doi.org/10.1007/s00234-011-0948-X

[7] Chalouhi, N., Tjoumakaris, S.I., Gonzalez, L.F., Hasan, D., Pema, P.J., Gould, G., Rosenwasser, R.H. and Jabbour, P.M. (2013) Spontaneous Delayed Migration/Shortening of the Pipeline Embolization Device: Report of 5 Cases. American Journal of Neuroradiology, 34, 2326-2330. http://dx.doi.org/10.3174/ajnr.A3632

[8] Lubicz, B., Collignon, L., Raphaeli, G., Pruvo, J.P., Bruneau, M., De Witte, O. and Leclerc, X. (2010) Flow-Diverter stent for the Endovascular Treatment of Intracranial Aneurysms: A Prospective Study in 29 Patients with 34 Aneurysms. Stroke, 41, 2247-2253. http://dx.doi.org/10.1161/STROKEAHA.110.589911

[9] McTaggart, R.A., Santarelli, J.G., Marcellus, M.L., Steinberg, G.K., Dodd, R.L., Do, H.M. and Marks, M.P. (2013) Delayed Retraction of the Pipeline Embolization Device and Corking Failure: Pitfalls of Pipeline Embolization Device Placement in the Setting of a Ruptured aneurysm. Neurosurgery, 72, onsE245-250; discussion onsE250-241.

[10] Pistocchi, S., Blanc, R., Bartolini, B. and Piotin, M. (2012) Flow Diverters at and Beyond the Level of the Circle of Willis for the Treatment of Intracranial Aneurysms. Stroke, 43, 1032-1038. http://dx.doi.org/10.1161/STROKEAHA.111.636019

[11] Lubicz, B., Collignon, L., Raphaeli, G. and De Witte, O. (2011) Pipeline Flow-Diverter Stent for Endovascular Treatment of Intracranial Aneurysms: Preliminary Experience in 20 Patients with 27 Aneurysms. World Neurosurgery, 76, 114-119. http://dx.doi.org/10.1016/j.wneu.2011.02.015

[12] Gao, B. and Malek, A.M. (2010) Possible Mechanisms for Delayed Migration of the Closed Cell—Designed Enterprise stent When Used in the Adjunctive Treatment of a Basilar Artery Aneurysm. American Journal of Neuroradiology, 31, E85-E86. http://dx.doi.org/10.3174/ajnr.A2258

[13] Rodriguez, G.J., Maud, A. and Taylor, R.A. (2009) Another Delayed Migration of an Enterprise Stent. American Journal of Neuroradiology, 30, E57. http://dx.doi.org/10.3174/ajnr.A1418

[14] Levy, E.I., Boulos, A.S., Hanel, R.A., Tio, F.O., Alberico, R.A., Fronckowiak, M.D., Nemes, B., Paciorek, A.M., Guterman, L.R. and Hopkins, L.N. (2003) In Vivo Model of Intracranial Stent Implantation: A Pilot Study to Examine the Histological Response of Cerebral Vessels after Randomized Implantation of Heparin-Coated and Uncoated Endoluminal Stents in a Blinded Fashion. Journal of Neurosurgery, 98, 544-553. http://dx.doi.org/10.3171/jns.2003.98.3.0544

[15] Ozaki, M., Murayama, Y., Ebara, M., Takao, H. and Abe, T. (2011) Delayed Hydrocephalus after Embolization of Unruptured Aneurysms Using Bare Platinum Coils: Report of 2 Cases. American Journal of Neuroradiology, 32, E188-E190. http://dx.doi.org/10.3174/ajnr.A2317 
Scientific Research Publishing (SCIRP) is one of the largest Open Access journal publishers. It is currently publishing more than 200 open access, online, peer-reviewed journals covering a wide range of academic disciplines. SCIRP serves the worldwide academic communities and contributes to the progress and application of science with its publication.

Other selected journals from SCIRP are listed as below. Submit your manuscript to us via either submit@scirp.org or Online Submission Portal.
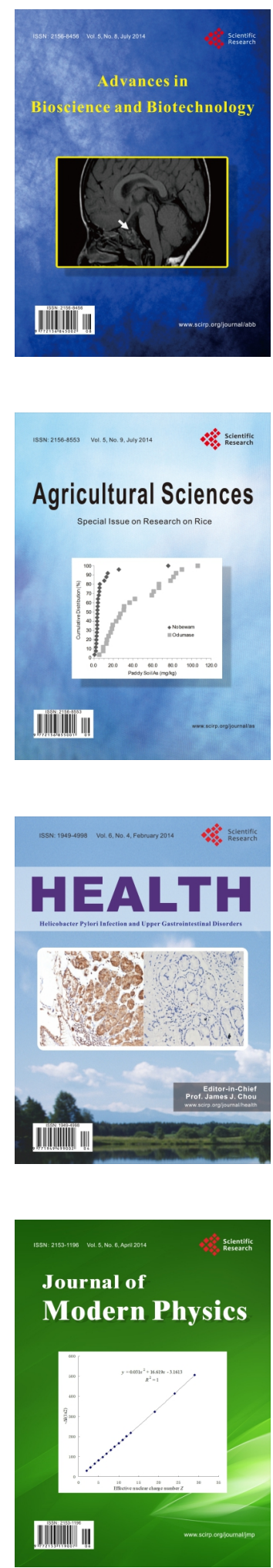
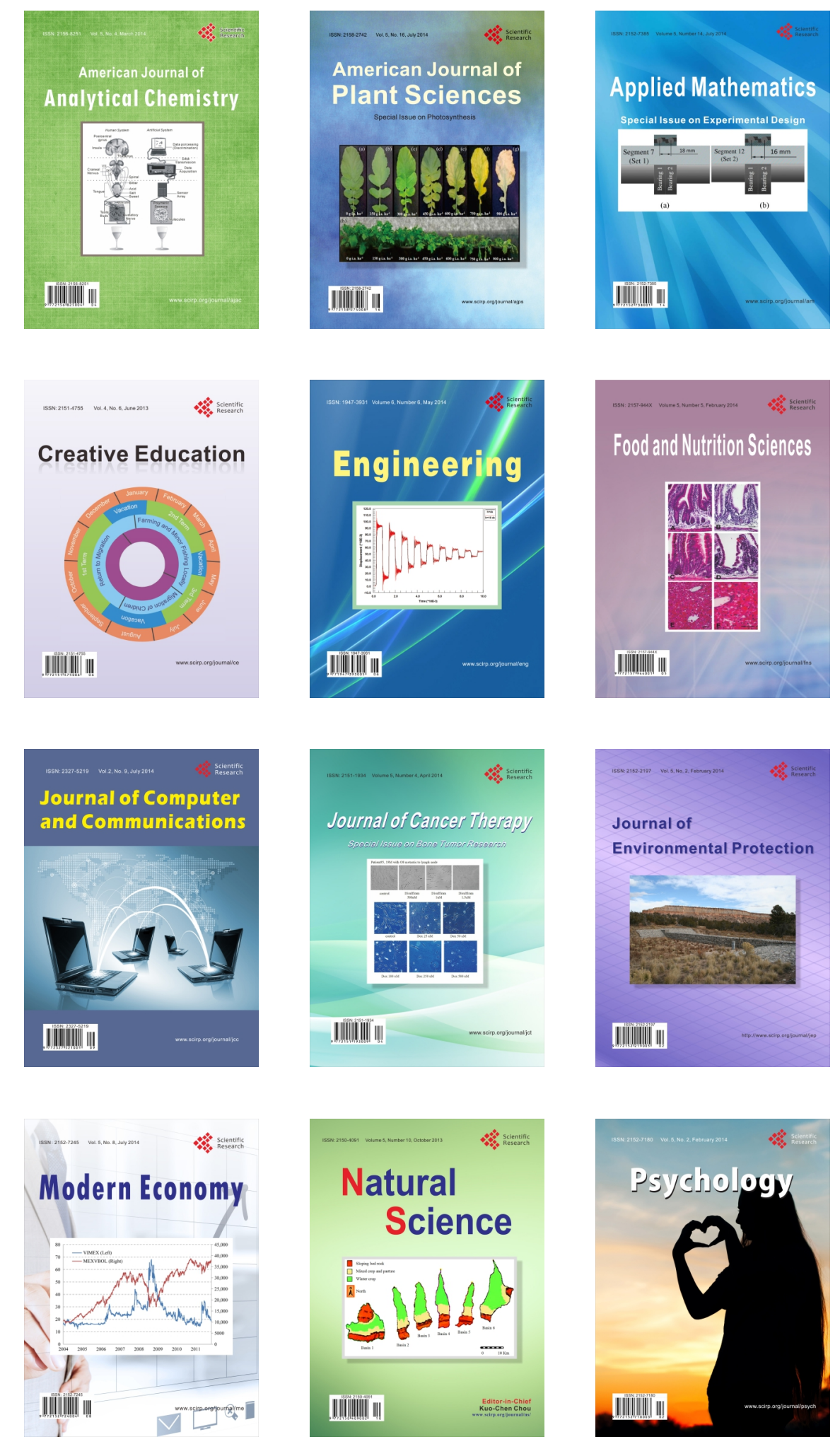